\section{Blogs: sentimentos em rede compartilhados na pós-modernidade}

\section{RESUMO}

Este artigo relaciona o surgimento dos weblogs com aspectos de pós-modernidade que se apresentam na contemporaneidade.

\section{ABSTRACT}

This paper deals with weblogs and their relationship with some contemporary characteristics of our postmodern condition.

\section{PALAVRAS-CHAVE (KEY WORDS)}

- Weblogs

- Pós-modernidade (Postmodernity)

- Internet

\section{Introdução}

EM TEMPOS DE EUFORIA e celebração ao mundo virtual (vide os filmes de ficção como a trilogia Matrix), a avalanche de games que permeia o mundo dos teenagers, adultos e crianças, ou ainda junto ao meio acadêmico no qual se tornam cada dia mais freqüentes as referências à categoria de imaginário da cibercultura/ciberespaço, faz-se pertinente considerar também os aspectos extramaquinísticos dos processos de comunicação contemporâneos. Uma vez que o determinismo tecnológico não deve guiar o espírito do pesquisador que se permite descrever as formas atuais das relações sociais, preocupado com aquilo que é, e não com aquilo que deve ser uma sociedade (visão fenomenológica do social) conforme polemiza Michel Maffesoli.

Neste artigo, de caráter de aproximação do objeto, tem-se uma inserção no universo da cibercultura a partir do surgimento dos weblogs, também chamados de blogs, ou seja, diários virtuais que se proliferam na internet como ferramentas de uma narrativa híbrida (misto de diários, crônicas jornalísticas e correspondências), que representa, simultaneamente, a individualidade e a coletividade, dimensões presentes no imaginário da sociedade pós-moderna. Essa tecnologia apresenta-se como uma nova forma de comunicação, cuja principal distinção é o elogio à subjetividade.

Entende-se que o blog representaria, na sua forma e conteúdo, os contornos de uma nascente sociedade pós-moderna, que privilegia a ética da estética, ou seja, de ser apenas em relação ao outro, de reconhecer-se no outro a partir do compartilhamento de sentimentos, idéias e

Paula Jung Rocha 
atitudes.

Sendo assim, o blog, na sua essência (diário virtual) teria tamanha repercussão na contemporaneidade em função de ser produto e (re)produtor de uma parcela de indivíduos que encontra na rede a possibilidade de se comunicar com o outro, de tocar o outro através de uma narrativa bem particular que pode variar desde a confecção de artigos, crônicas, até a exposição de fatos e histórias de interesses peculiares como poesia, fotografias e relatos autobiográficos.

Quando se trata de comunicação, globalização e tecnologia, assuntos pertinentes no período de transição deste novo século, se pensa na agregação desses elementos através da concretização da internet, isto é, uma rede global de informações linkadas em tempo real em permanente conexão ao ciberespaço a partir de um computador e um transmissor que pode ser a cabo, modem ou rádio. Resultado de um ambicioso projeto tecnológico que tinha como pressupostos arquivar informações e suprimir distâncias para que mensagens chegassem a diversos locais de maneira segura e veloz, a internet transcende os objetivos militares e se consagra hoje como um fenômeno da comunicação ao se tornar uma tecnologia de fundamental importância na construção do imaginário da pós-modernidade.

Não há dúvidas de que se vive um momento tecnológico/social sem precedentes na história do homem. A tecnosfera é a realidade pela qual transita ou paira a sociedade contemporânea. Os sentimentos de medo e de desconfiança diante das novas tecnologias, característicos da modernidade, convivem com a fascinação e a proliferação avassaladora do instrumento tecnológico, sobretudo quando o assunto é rede de comunicações e suas demais implicações como alta velocidade, supressão de espaço/tempo, capacidade de interatividade, simulação, inteligência artificial.
A internet transforma o processo de comunicação. A fórmula cartesiana emissor-mensagem-receptor é substituída pela confluência desses elementos numa ordem que não respeita a priori. O usuário é ao mesmo tempo o manipulador da mensagem e a própria mensagem.

Essa natureza anárquica suscita reflexão por parte daqueles que compreendem que determinada situação se consolida apenas a partir da adesão de um número cada vez maior de indivíduos envolvidos com as novas tecnologias de comunicação, o que por sua vez indicaria o nascimento da cibercultura, isto é, a relação social de sujeitos que se dá no plano virtual.

Após um período de intensa produção de home pages; interações em chats e games, o ciberespaço conta atualmente com a invasão de um novo tipo de configuração disponível aos internautas para a confecção de suas próprias páginas em linguagem mais acessível, se comparada à HTML, a todos aqueles que pretendem se comunicar através da rede, são os chamados blogs ou diários eletrônicos.

No surgimento dos blogs, salienta-se o fato de que tais suportes facilitam a entrada e a circulação de um amplo conjunto de indivíduos (muitos não possuem o domínio da técnica) no espaço virtual, promovendo uma maior concentração de internautas e, portanto, contribuindo para a expansão da socialidade em rede, a cibercultura.

Pode-se afirmar que o processo de desenvolvimento da internet e de suas modulações, no caso deste trabalho os blogs, se relaciona com o imaginário tecnológico/social do qual fazem parte. Uma vez que a sociedade é produtora de uma sociedade que a produz, como diz Edgar Morin, a evolução das tecnologias seria, ao mesmo tempo, produto e elemento desencadeador de uma configuração societal que se apresenta na contemporaneidade.

Essa configuração engendrada a 
partir da relação do homem com a técnica passa por diversas fases. A forma pela qual se apresenta hoje é o reflexo de uma série de mudanças ocorridas no imaginário de cada época. A própria palavra imaginário, relegada a segundo plano pela modernidade em nome da supremacia da razão, adquire atualmente o estatuto principal para quem pretende estudar os fenômenos sociais, pois segundo Michel Maffesoli o imaginário seria o espírito coletivo da sociedade.

Ao acreditar que o imaginário contemporâneo retoma características arcaicas, como se pode verificar nas abordagens de Maffesoli a respeito das tribalizações, este trabalho aponta a relação das novas tecnologias (representadas pelos blogs) no imaginário da pós-modernidade a partir da constatação do fenômeno da cibercultura, cuja intensidade é observada com os diversos tipos de contatos que se estabelecem no ciberespaço.

Observa-se empiricamente que as narrativas presentes nos variados tipos de blogs resgatam, muitas vezes, valores afetivos. Nota-se a diferença de apresentação entre o correio eletrônico (e-mail), geralmente constituído por um texto curto e uma linguagem direta, e a possibilidade de se utilizar um blog para criar distintos formatos textuais que remontam às correspondências tradicionais, as quais se acreditava estarem fadadas a desaparecer justamente pelo avanço das novas tecnologias.

Ao aceitar uma condição pós-moderna da existência, o trabalho trata da questão tecnológica na sociedade contemporânea a partir da constatação sobre a evidente cibercultura que se anuncia na vida social e que portanto implica a reestruturação das novas formas de comunicação. Os preceitos de presenteísmo, tribalismo, estar-junto, ideal comunitário, hedonismo, retratados por Maffesoli poderiam descrever a relação atual da comunicação com os atores sociais e, por outro lado, a passividade da massa, a ausência de valores da sociedade, enunciados por Jean Baudrillard também seriam componentes da identidade ou das identificações do homem contemporâneo.

Até que ponto pode-se dizer que a técnica em todos os seus domínios contribuiria para o esvaziamento do sujeito ou, ao contrário, promoveria o enaltecimento do mesmo? A fim de encontrar elementos para essa análise seria necessário retomar pensadores como Nietzsche, Heidegger, Simmel, entre outros que tratam da questão da técnica, da sua essência e de seus desdobramentos na vida do homem. Todavia, o recorte desse artigo conta com autores como Michel Maffesoli, Pierre Lévy, André Lemos, Marshall McLuhan.

Ao descrever o processo de surgimento e as identidades dos usuários de blogs pretende-se relacionar esse novo meio (forma de comunicação) como sendo uma ferramenta tecnológica do imaginário na contemporaneidade. Não seriam os blogs os herdeiros de diversos gêneros literários e jornalísticos na era da cibercultura?

\section{Blogs: prazer em conhecê-los!1}

Alguns pesquisadores da recente história do weblog afirmam ter sido usado pela primeira vez em dezembro de 1997, por John Barger, para descrever sites pessoais que fossem atualizados freqüentemente e contivessem comentários e links. Para outros, o primeiro weblog foi o primeiro website, o site construído por Tim BernersLee quando foi criada a Web.

O termo blog é um jargão derivado da união das palavras inglesas web (rede) e log (diário de bordo onde os navegadores registravam os eventos das viagens, principalmente aqueles ligados ao clima). No caso do blog, portanto, tratase de uma abreviatura de weblog, na qual web representa a própria internet, e log caracteriza os registros que são realizados 
pelo usuário do blog - o blogger (blogueiro).

Portanto, o blog pode ser considerado um diário eletrônico que as pessoas criam na Internet. Do ponto de vista da sua forma, o blog se confunde com o conceito de web page ou site pessoais construídos na web. $O$ que distingue o blog de um site convencional é a facilidade com que se pode fazer registros para a sua atualização, o que o torna muito mais dinâmico do que os sites. O dicionário MarketingTerms.com define blog como uma publicação freqüente e cronológica de pensamentos pessoais e de links da web. Considera-se o blog uma mistura dos acontecimentos na vida das pessoas e dos acontecimentos na web, uma espécie híbrida de diário pessoal/guia de sites.

Mas isto seria apenas uma conceituação didática, estática, da ferramenta digital blog. Sob o ângulo da sua funcionalidade, o blog se diferencia de todas as outras formas de relacionamento virtual (e-mail, chats, instant messages, listas de discussão, etc.) justamente pela sua dinamicidade e interação possibilitadas pela facilidade de acesso e de atualização. Devido a essas características básicas, 0 blog parece trazer vida à web, a ponto de muitos analistas e usuários considerarem que essa nova forma de comunicação e de relacionamento virtual tornou-se moda na web. Outros consideram o blog como o futuro da publicação de escritos pessoais. Alguns mais entusiasmados chegam a designar o blog como a versão on-line de uma renascença digital, dado o potencial que enxergam nesta ferramenta que começou com a humildade da simples idéia de diário pessoal e guia de sites on-line. Há aqueles que conceituam o blog como um laboratório de escritos criativos, cujo principal objetivo é oferecer à comunidade de escritores e leitores um local virtual onde possam se encontrar e interagir, trocando experiências, motivações, idéias e informações sobre temas de mútuo interesse. Poderia, assim, ser considerado, pois, uma incubadora de comunidades de internautas com interesses comuns.

Pela personalidade e interatividade dos participantes das comunidades blogueiras, muitos consideram que a atividade blogueira - o blogging - chega a lembrar a contracultura, com sabor de faça você mesmo: faça a sua própria mídia se a mídia institucionalizada não aceitar você. No seu conceito mais simples o blog pode, então, ser concebido como um diário pessoal, uma home page ou um site personalizado, dinâmico e interativo, atualizado freqüentemente, quando o blogueiro quiser ou puder, com registros em ordem cronológica inversa (o último lançamento aparecendo sempre em primeiro lugar), utilizando programas simples que praticamente exigem apenas conhecimentos elementares de informática por parte do blogueiro. A única grande exigência é que o candidato queira ser internauta.

O conceito de blog está sendo ampliado e aplicado com o nome do assunto onde o blog é utilizado, como no caso do gerenciamento do conhecimento (knowledge, em inglês), daí resultando o klogging (knowledge-logging). Segundo John Robb (http://jrobb.userland.com), apesar de novo, o desenvolvimento deste conceito fará com que seja possível a qualquer empregado de uma empresa adquirir e/ ou adicionar conhecimentos na intranet da mesma, formando uma knowledge network na organização, tudo baseado no fácil entendimento dos conceitos básicos de blog e da web. Um blogueiro pode ter (e habitualmente tem...) vários blogs, em várias partes do mundo, cada um tratando de um tema específico, ou atendendo ao estado de espírito do seu dono no momento de fazer os registros... Ou, ao contrário, pode não ter nenhum blog pessoal, individual, e ficar somente escrevendo em blogs públicos ou adicionando comentários nos blogs dos outros.

Imaginário tecnológico 
Pensar o imaginário tecnológico implica considerar a questão do desenvolvimento das técnicas de comunicação/informação e a sua relação com os fenômenos societais.

Para cada fase do desenvolvimento tecnológico corresponde uma certa característica principal. $\mathrm{Na}$ modernidade, o avanço tecnocientífico faz com que a humanidade alcance um nível de progresso sem precedentes, a chamada fase de conforto. $\mathrm{Na}$ contemporaneidade, período que pode ser também denominado como de transição da modernidade para a pósmodernidade, os caminhos tecnológicos já consagrados tomam rumos diferentes. Passados os primeiros momentos de medo e fascinação diante da relação homem-máquina, vive-se, hoje, em um ambiente que comporta a socialidade e a tecnossocialidade. As novas tecnologias proporcionam, além do aspecto da ubiqüidade, o nascimento da cibercultura (ou tecnossocialidade).

As redes de comunicação, estabelecidas como ideais da modernidade, a fim de ligar o mundo e suas partes, se efetuam, na contemporaneidade, também no ciberespaço, ampliando ainda mais a possibilidade de troca de conhecimentos e a democratização do direito de acesso à informação.

Em meio a esse contexto e à pertinência da reflexão sobre as novas tecnologias de comunicação e informação, a intenção deste trabalho - sua problemática - é compreender e analisar a "onda" dos weblogs como uma possível nova forma de comunicação pós-moderna.

Uma vez que se acredita na possibilidade da concretização dessa comunicação em função de uma retribalização de grupos da sociedade através do desenvolvimento das novas tecnologias.

O principal teórico norteador do trabalho é Michel Maffesoli, devido a sua definição provisória de que a pósmodernidade seria a conjunção entre o arcaico com o tecnológico. A partir dessa premissa, este estudo trata de descrever um breve relato do contexto contemporâneo, a importância das tecnologias do imaginário e a existência dos weblogs, os quais refletiriam uma nova maneira de "estar-junto" na contemporaneidade cuja aparência revela agregações de indivíduos a partir de uma ordem que parece privilegiar as coisas próximas, domésticas (ideal comunitário), em um ambiente de emoção, sentimento em relação ao outro, tanto no plano presencial quanto nos encontros virtuais proporcionados pela disseminação de imagens e de contatos no ciberespaço.

O fundamento metodológico desta pesquisa encontra-se no paradigma da Complexidade e na Sociologia Compreensiva, porque somente os princípios que entendem a dialógica e a autonomia/dependência dos fenômenos contemporâneos desenvolvidos por Morin cruzam-se com a razão sensível na qual se debruça Maffesoli para explicar e compreender o resgate de valores arcaicos, que se cristalizam na contemporaneidade.

A necessidade de um pensamento dialógico faz-se pertinente, uma vez que os fenômenos atuais exigem uma interpretação complexa devido à relação hologramática entre o todo e as partes e as partes e o todo. Um olhar que contemple as paradoxais formas presentes na sociedade, a fim de se aproximar e de descrever os elementos que a compõem, sem a preocupação com julgamentos de uma sociologia ortodoxa.

Maffesoli (1995) tem uma opinião coerente sobre a impossibilidade de se explicar o mundo de hoje com os olhos voltados ao passado, tempo esse deveras comprometido com as filosofias econômicas. Para ele, as transformações, ocorridas principalmente a partir da Segunda Guerra Mundial, trazem à tona as incertezas de um mundo sedimentado apenas em estruturas racionais.

Com a falência dos discursos 
modernos, que prometiam um mundo redentor, aliada à velocidade das inovações técnicas, o homem contemporâneo procura relacionar a sua vida a preceitos presenteístas (culto ao hedonismo, valorização do doméstico, barroquização da existência, vínculo comunitário, imersão no universo das redes tecnológicas de comunicação, prevalência da estética, resgate dos valores dionisíacos, lúdicos, oníricos, etc.) porque parecem ser mais condizentes com o estilo de vida atual ${ }^{2}$, o qual agrega o racional, o irracional, o nãoracional, o lógico, o não-lógico e o ilógico.

Essa é uma época de fermentação. Devido à transição da modernidade para a pós-modernidade, há uma massa perturbadora no ar que faz com que os instintos mais sensíveis reconheçam um novo modo de "estar-junto" contemporâneo. Ainda em formação, há de se pensar a respeito da cristalização de um estilo estético que parece estar aflorando.

Marca da modernidade, o individualismo perde espaço no momento em que se reconhece que o homem não é o senhor do universo. O reordenamento social aponta para o reconhecimento do outro a partir de uma identificação de afetos e interesses compartilhados. Os indivíduos se aproximam com a intenção de se solidarizar com a causa do outro. O laço social passa a ser emocional. O contrato não vale para confirmar uma identificação que pode ser passageira e múltipla. "Não é mais a autonomia - eu sou minha lei - que prevalece, mas a heteronomia: minha lei é o outro." A decepção político-econômica leva à revalorização das coisas domésticas, da proximidade (Maffesoli, 2001: 25).

Ao analisar a contemporaneidade, Maffesoli (2001), que não acredita em conceitos fechados, define a pósmodernidade como uma época de heterogeneização. Mistura orgânica de elementos arcaicos e de outros um pouco mais contemporâneos, que inaugura uma forma de solidariedade social elaborada a partir de um processo complexo feito de atrações, de repulsões, de emoções e de paixões, que tanto pode levar à concretização de ações humanitárias quanto à volta de ideais fundamentalistas, da qual se falou anteriormente.

Aceitar a condição de pósmodernidade implica considerar diversos aspectos que a caracterizam. Ao estabelecer que há realmente uma alternância do dado social, é necessário estudar os fatos que conduzem tal mudança, os quais podem ser analisados através dos fenômenos culturais refletidos a partir de uma dimensão não-racional presente na sociedade, chamada de imaginário. Fala-se em imaginário e cultura porque são estes elementos, segundo Maffesoli (1995), que produzem e interagem com a concepção de mundo que se tem em cada época.

Maffesoli reconhece a forma lúdica e o resgate dos valores dionisíacos na contemporaneidade quando diz que a própria sociedade torna-se um jogo de simulação a partir da intensidade dos jogos eletrônicos, da flutuação das bolsas econômicas e das encenações políticas. $O$ hedonismo mundano é o prazer de estarjunto, cujo destaque se dá através do jogo das imagens e da sua disseminação virótica. A lógica da teatralização pósmoderna, na qual as personas utilizam múltiplas máscaras, está na ordem do dia, dentro de um tempo que se identifica através da ética e não da moral.

Segundo o autor, a moral é universal e aplicável em todos os lugares e em todos os tempos. Já a ética é particular, às vezes momentânea, que fundamenta uma comunidade e elabora-se sobre um território dado, seja ele real ou simbólico (Maffesoli, 1996).

Nota-se a emergência de um novo estar-junto baseado na ética da estética, uma espécie de simpatia em relação ao outro. A emoção é vivenciada coletivamente, dentro de um ambiente afetuoso, cujos "prazeres e penas são experimentados em comum" (Maffesoli, 1995: 76), seja através 
de manifestações presenciais (shows, greves, passeatas, reuniões), ou a partir da disseminação do uso das tecnologias do imaginário (televisão, rádio, cinema, Internet, publicidade, etc.), as quais transmitem imagens e eventos que passam a ser compartilhados coletivamente. Como o próprio nome indica, são as mensagens imagéticas, sonoras e textuais -, divulgadas através das tecnologias de comunicação, elementos fundamentais na construção do imaginário.

A idéia da existência de tecnologias do imaginário relaciona-se com as técnicas de comunicação (televisão, literatura, cinema, internet, etc.) que possam interferir no processo de construção do imaginário. A respeito do imaginário pode-se dizer que esse "conceito" está imbricado no gênio coletivo e, portanto, reflete o espírito de uma sociedade, que por sua vez definese como "a relação entre intimações objetivas e subjetivas" (Maffesoli, in Revista FAMECOS, 2001).

A necessidade de recuperar a noção de imaginário para descrever a contemporaneidade se dá pelo fato de que, segundo Maffesoli, há uma valorização da técnica na atualidade, uma vez que o imaginário é alimentado por tecnologias. Sendo assim, "neste momento histórico de intenso desenvolvimento tecnológico, ainda mais nas tecnologias de comunicação, a repercussão do imaginário, enquanto comunhão, é sempre comunicação" (in Revista FAMECOS, 2001).

Segundo o autor, a Internet faz-se mais importante devido ao seu aspecto simbólico, através de um espaço de circulação de signos e atividades interpessoais, do que em relação à sua concepção racional e utilitarista. Assim ocorre também com a televisão e a publicidade, ambas agentes de emoção e estruturadas pela tecnologia.

Visto que a tecnologia foi durante a modernidade um instrumento de racionalização e de separação, parece que na contemporaneidade $\mathrm{o}$ aparato tecnológico está a transformar-se numa ferramenta convivial e comunitária.

A socialidade contemporânea vai se estabelecer, então, como um politeísmo de valores onde o indivíduo desempenha papéis, produzindo máscaras dele mesmo, agindo numa verdadeira teatralidade quotidiana.

Ao invés de inibir as situações lúdicas, comunitárias e imaginárias da vida social, as novas tecnologias vão agir como vetores potencializadores dessas situações, da socialidade (Lemos, 2002: 90).

Se na modernidade o indivíduo tinha uma função, a pessoa (persona) pós-moderna tem um papel, mesmo que efêmero, hedonista ou cínico, e isso não significa que esse fato seja novo, mas afirma que a preponderância da persona sobre o indivíduo atinge seu paroxismo nesse momento. Segundo Maffesoli, a forma exprime melhor a cultura vigente.

Neste sentido, faz-se necessário o reconhecimento do importante papel desempenhado pelo professor canadense Marshall McLuhan, ao estabelecer, na década de 60 , significativos conceitos a respeito da mídia eletrônica. Principalmente, observa-se o caráter profético de suas argumentações referentes à aldeia global, expressão que, atualmente, se torna uma realidade, devido à viabilidade do fenômeno da globalização existente nos campos estruturais da sociedade, sejam estes econômico, cultural, social, comunicacional ou político.

O pioneirismo de McLuhan relacionase com a sensibilidade do autor em perceber o que realmente significam os meios de comunicação e, sobretudo, como eles afetam a vida das pessoas. A fim de explicar a sua teoria de que os indivíduos são modificados por suas tecnologias de comunicação, o professor canadense formula a hipótese de que as tecnologias constituem uma extensão dos sentidos 
humanos, os quais refletem o predomínio de um tipo ou outro de percepção da realidade.

Apenas através do advento da escrita tem-se a possibilidade de articulação das noções atribuídas ao tempo: passado e presente. A fim de explicar a história da comunicação, o autor distingue dois períodos revolucionários: a época de Gutenberg e a época eletrônica do audiovisual.

O descobrimento da escrita e, mais tarde, das técnicas de impressão destribalizou a humanidade. Rompeu a associação entre os sentidos e modificou a maneira de o homem perceber e se relacionar com o mundo, tornandoa solitária, técnica, fria e impessoal. Favoreceu certos sentidos, como a visão, em detrimento de outros, ao mesmo tempo em que engendrou uma determinada forma de racionalidade bastante limitadora. Ao separar o homem do acontecimento, o processo de comunicação torna-se passível de alterações que podem afetar e modificar a mensagem original.

A era eletrônica possibilita o compartilhamento do processo criativo e do saber, coletivamente, devido ao resgate da oralidade. Neste caso, a extensão se efetuaria através da criação de meios de comunicação de massa capazes de recuperar uma unidade dos sentidos que faria do mundo uma única grande tribo. Ocorre, assim, uma democratização dos conhecimentos. Ressalta-se que o seu foco, na época, era a utilização da televisão.

A respeito da tese de McLuhan sobre o processo de retribalização, que ocorre como resultado da tecnologia elétrica, Lemos analisa o fato de que os computadores em rede se aproximam mais de uma época anterior à escrita $e$ à imprensa, remetendo a um estado de tribalização da humanidade. De acordo com o autor:

Podemos dizer que a dinâmica social atual do ciberespaço nada mais é do que esse desejo de conexão se realizando de forma planetária. Ele é a transformação do PC (Personal Computer), o computador individual, desconectado, austero, feito para um indivíduo racional e objetivo, em um CC (Computador Coletivo), os computadores em rede. Assim, a conjunção de uma tecnologia retribalizante (o ciberespaço) com a socialidade contemporânea vai produzir a ciber-cultura profetizada por McLuhan (Lemos, 2002: 76).

A fim de se reconhecer a relevância da obra de McLuhan, ao propor ineditamente a expressão de aldeia global, encontra-se na narrativa de Pierre Lévy uma essência propulsora do fenômeno da globalização. $O$ autor defende o estatuto da Internet como um meio capaz de promover o encontro dos homens. "A humanidade reconecta-se consigo mesma." (Lévy, 1999: 195)

Conforme expressou McLuhan, sobre a necessidade do resgate dos sentidos, Lévy também acredita na possibilidade de recuperação da unidade do sentido. Porém, ele faz esta leitura através do objeto de análise: a Internet e as alterações causadas pela mesma nos indivíduos e na sociedade. Segundo o autor, o ciberespaço e a cibercultura são os fenômenos que representam, hoje, a totalidade da mudança introduzida por esta nova mídia. "A revolução contemporânea das comunicações, da qual a emergência do ciberespaço é a manifestação mais marcante, é apenas uma das dimensões de uma mutação antropológica de grande amplitude." (Lévy, 1999: 195)

Segundo ele, o recurso da Internet reflete novamente uma característica da comunicação oral. Ao acessar chats e home pages, ou enviar informações através de correios eletrônicos, há uma troca de mensagem instantânea. O resultado da comunicação verifica-se no momento em que 0 receptor e o emissor estabelecem 
contato.

Diferentemente da comunicação escrita, que não oportuniza um contato imediato, este seria o momento do regresso à era da oralidade. No entanto, esta seria uma oralidade mais abrangente e especializada. Hoje, além de todos os efeitos de uma comunicação oral, temse a oportunidade de complementar a comunicação com ferramentas capazes de editar imagens e áudio, traduzir textos em diversas línguas, elaborar pesquisas, realizar colóquios on-line; enfim, facilitar e aprimorar o conhecimento e a coletividade humana, simplesmente através de uma conexão com o ciberespaço, o que se torna mais acessível devido à redução dos preços dos computadores e dos aparatos técnicos necessários à navegação. O desenvolvimento de uma interface mais amigável também aproxima o computador do usuário leigo.

Esta infinita rede digital está sendo tecida pelos principais países do mundo, com a pretensão de envolver a todos num espaço virtual, chamado ciberespaço, no qual as culturas particulares fundem-se, a fim de formarem uma única cultura global e cibernética.

Conforme teoriza o autor, o espaço virtual é um agente libertador, porque não segue os padrões dos meios de comunicação como a televisão, o rádio ou o jornal, que são essencialmente meios de censura e de poder político. A natureza da Internet, livre do processo de hierarquização e de controle, leva o homem a optar por seus próprios caminhos, divulgá-los a quem se interessar e, principalmente, induz ao compartilhamento dos sentidos.

A cibercultura leva a co-presença das mensagens a seu contexto como ocorria nas sociedades orais, mas em outra escala, em órbita completamente diferente. A nova universalidade não depende mais da auto-suficiência dos textos, de uma fixação e de uma independência das significações. Ela se constrói e se estende por meio da interconexão das mensagens entre si, por meio de sua vinculação permanente com as comunidades virtuais em criação, que Ihes dão sentidos variados em uma renovação permanente (Lévy, 1999: 15).

Supondo que a profecia de McLuhan esteja mais do que nunca se concretizando em termos de estruturas tecnológicas, deve-se pensar a respeito do papel fundamental das tecnologias do imaginário na busca de estabelecer uma consciência coletiva universal na imensa aldeia global que é o planeta Terra.

Também se nota que essa forma contemporânea reinveste em temas arcaicos, referências míticas ou imagens dos bons e velhos tempos. Repete de maneira cíclica o que se acreditava estar ultrapassado; o reencantamento, o imaginário, o simbólico, o onírico, o festivo exprimem esse processo, de modo que os arcaísmos são reinvestidos e reutilizados pelos diversos meios do desenvolvimento tecnológico. "É um movimento em espiral, onde o retorno ao mesmo sofre uma alteração de importância, que é trazida pela tecnologia de ponta." (Maffesoli, 1995: 147).

Assim, "assiste-se ao nascimento de uma verdadeira subjetividade de massas, que repousa sobre o contágio afetivo, sobre a partilha dos sentimentos e sobre a participação nas emoções comuns. Há fanatismo no ar" (Maffesoli, 1990: 51), que pode ser encontrado em diversos momentos da sociedade contemporânea, na qual as formas cristalizadas definem o modo de ser da contemporaneidade. Neste caso, os weblogs podem ser os expoentes de um novo estar-junto que acontece no ciberespaço. Mas nem por isso é menos produtor de cibersocialidade . 


\section{Notas}

1 Informações coletadas nos sites www.globo.com.br e www.terra.com.br.

2 Lembra-se que 0 estilo de vida atual, denominado por alguns autores como pós-modernidade, é apenas uma etiqueta, um rótulo que serve de denominação para um estado de coisas que se apresenta na contemporaneidade. Não há nenhum rigor em afirmar por que se valorizam determinados valores, mas sim em constatar tal evidência.

\section{Referências}

LEMOS, André. Cibercultura: tecnologia e vida social na cultura contemporânea. Porto Alegre: Sulina, 2002.

LÉVY, Pierre. A conexão planetária: o mercado, o ciberespaço, a consciência. São Paulo: Editora 34, 2001.

A máquina universo: criação, cognição e cultura informática. Porto Alegre: ArtMed, 1998.

As tecnologias da inteligência: o futuro do pensamento na era da informática. São Paulo: Editora 34, 1993.

. Cibercultura. São Paulo: Editora 34, 1999.

O que é o virtual? São Paulo: Editora 34, 1996.

MAFFESOLI, Michel. A conquista do presente. Natal: Argos, 2001.

A contemplação do mundo. Porto Alegre: Artes e Ofícios, 1995.

A violência totalitária. Ensaio de antropologia política.

Porto Alegre: Sulina, 2001.

No fundo das aparências. Petrópolis: Vozes, 1999.

. 0 Conhecimento Comum. Compêndio da Sociologia

Compreensiva. São Paulo: Brasiliense, 1988.

. 0 tempo das tribos, o declínio do individualismo nas

sociedades de massa. Rio de Janeiro: Forense, 1998.
MCLUHAN, Marshall. Os meios de comunicação como extensões do homem. São Paulo: Cultrix, 1964.

MORIN, Edgar. A cabeça bem-feita: Repensar a reforma, reformar o pensamento. Rio de Janeiro: Bertrand Brasil, 2002.

. As duas globalizações. Porto Alegre: Sulina, 2001.

. 0 Método 1. Porto Alegre: Sulina, 2002.

0 Método 2. Porto Alegre: Sulina, 2001.

RÜDIGER, Francisco. Capítulos de arqueologia espiritual pósmoderna. Sujeito e objeto na aurora da Cibercultura. Porto Alegre: E@, 2002. 